\title{
Rancang Bangun Portable Monitoring Suhu Lingkungan Berbasis Internet Of Things
}

\author{
Yoedo Ageng Suryo S.S.T., M.T \\ Fakultas Teknik Program Studi Teknik Elektro Universitas Muhammadiyah Gresik \\ Jl. Sumatera No.101 GKB, Randuagung, Kec. Kebomas, Kab. Gresik, Jawa Timur 61121 \\ mryoedo@umg.ac.id
}

\begin{abstract}
Abstrak - Perancangan sistem monitoring suhu yang portable akan menjawab kebutuhan akuisisi data yang tidak terbatas tempat dan waktu. Ketergantungan terhadap sumber daya menjadi faktor penentu utama portabilitas sistem yang berbasis internet of things. Rancangan penelitian ini merupakan aktifitas monitoring suhu lingkungan dalam satuan Celcius yang bisa ditempatkan di manapun. Melibatkan komponen utama sebagai penunjang aktifitas monitoring berupa sensor suhu untuk mendapatkan data, mikrokontroler sebagai pengontrol kerja sistem dan GSM/GPRS serial modem sebagai modul komunikasi data. Pencatatan data berupa besaran suhu analog yang dikonversi dengan kenaikan $10 \mathrm{mV} /{ }^{\circ} \mathrm{C}$ dengan tingkat akurasi sebesar $0.5^{\circ} \mathrm{C}$. Pencatatan data hasil monitoring berpusat di server Thing speak yang dilakukan secara realtime. Pengguna dapat mengolah data yang diperlukan untuk keperluan analisis lebih lanjut. Berdasarkan perancangan sistem ini, didapatkan kemampuan untuk mengukur suhu dari $6^{\circ} \mathrm{C}$ sampai $100^{\circ} \mathrm{C}$ dengan error rata-rata sebesar $0.023^{\circ} \mathrm{C}$.
\end{abstract}

Kata kunci : portable, internet of things, monitoring, Thingspeak, realtime

\begin{abstract}
The design of a portable temperature monitoring system responses data acquisition that are not limited to time and place. Dependence on resources is the main issue of system portability based on internet of things. The design of this research is environmental temperature monitoring in Celsius which can be placed anywhere. Involving the main components as supporting monitoring activities like temperature sensor to obtain data, a microcontroller as the controller and GSM/GPRS serial modem as a data communication module. Recording data in the form of analog temperature quantities that are converted with an increase of $10 \mathrm{mV} / \mathrm{C}$ with an accuracy of $0.5^{\circ} \mathrm{C}$. The recording of monitoring data results is concentrated on the Thingspeak server which is done in realtime. User can process the data for further analysis. Based on the design of this system, it was obtained the ability to measure temperatures from $6^{\circ} \mathrm{C}$ to $100^{\circ} \mathrm{C}$ with an average error of $0.023^{\circ} \mathrm{C}$.
\end{abstract}

Keywords : portable, internet of things, monitoring, Thingspeak, realtime

\section{PENDAHULUAN}

Monitoring kondisi lingkungan, penting dilakukan untuk keperluan analisis terkait berbagai bidang disiplin ilmu. Kondisi yang dimaksud seperti pemantauan curah hujan, suhu dan kelembaban, tingkat pencemaran gas buang industri, debit air sungai dan lain sebagainya. Hal ini dapat dilakukan dengan cara meletakkan seperangkat modul untuk keperluan yang dimaksud di tempat tertentu. Penempatan modul ini harus mempertimbangkan beberapa titik vital untuk kepresisian data. Hal ini dilakukan sebagai alternatif pengamatan yang tidak memungkinkan secara manual. Proses pengumpulan data dapat ditempuh dengan merancang bangun alat untuk keperluan yang menyesuaikan kebutuhan. Tantangan teknologi dewasa ini menghendaki agar proses monitoring berjalan realtime dan hasilnya dapat dilihat secara online. Kebutuhan ini menghendaki adanya modul tambahan untuk keperluan komunikasi data supaya berjalan lancar.

Beberapa penelitian yang menekankan perlunya pemantauan kondisi lingkungan secara online, diantaranya dimanfaatkan untuk membantu budidaya jamur tiram menggunakan modul ESP 8266 [1]. Monitoring dilakukan pada suhu dan kelembaban pada nilai tertentu, untuk menyesuaikan kebutuhan perkembangan jamur tiram. Penelitian yang lain bertujuan menginformasikan pentingnya kualitas udara yang sehat melalui kombinasi wemos dan sensor MQ135 via website [2]. Pemantauan kondisi gas lingkungan dilakukan dengan menggunakan sensor gas MQ4 dan MQ135 yang dikombinasikan dengan modul ESP 8266. Besaran nilai gas selanjutnya dikirim melalui internet[3]. Beberapa penelitian yang disebutkan, memanfaatkan modul pengirim data melalui ESP 8266. Modul ini mengharuskan adanya keberadaan access point atau modem router supaya bisa terhubung dengan internet. Karena itu modul ESP 8266 bisa dikatakan sangat tergantung adana koneksi tambahan menuju akses internet. Sistem rancang bangun dalam penelitian ini menggunakan SIM900a sebagai alternatif modul komunikasi data melalui internet. Modul ini hanya membutuhkan simcard aktif untuk proses komunikasi.

Penelitian ini tidak hanya sekedar menekankan pendeteksian besaran suhu tertentu, tetapi juga dilengkapi adanya proses komunikasi data untuk melengkapi sistem monitoring melalui website. Alternatif modul yang digunakan hanya memerlukan kartu GSM dengan aktif 
data internet untuk keperluan komunikasi ke server. Pemantauan besaran suhu selanjutnya dapat digunakan untuk berbagai keperluan.

\section{STUDI PUSTAKA}

a. Sensor Suhu

Terdapat berbagai macam modul sensor suhu yang bisa dimanfaatkan. Pemilihan tipe sensor suhu menyesuaikan kondisi lingkungan dan kebutuhan rancang bangun sistem. Penyesuaian antara besaran suhu lingkungan dan sensor yang dibutuhkan, ditetapkan memilih LM35 keluaran vendor National Semiconductor. Salah satu faktor pemilhan dikarenakan adanya rentang pengukuran nilai yang cukup besar yaitu antara $-55^{\circ} \mathrm{C}$ sampai $150^{\circ} \mathrm{C}$. Rentang nilai ini cukup untuk kebutuhan pemantauan kondisi lingkungan di Indonesia. Spesifikasi sensor suhu LM 35 sebagaimana datasheet dapat dilihat di tabel 1 .

\begin{tabular}{cl} 
& \multicolumn{1}{c}{ Tabel 1. Spesifikasi LM35 } \\
\hline No. & \multicolumn{1}{c}{ Fitur } \\
\hline 1 & Calibrated directly in ${ }^{\circ}$ Celsius (Centigrade) \\
2 & Linear $+10.0 \mathrm{mV} /{ }^{\circ} \mathrm{C}$ scale factor \\
3 & $0.5^{\circ} \mathrm{C}$ accuracy guaranteeable $\left(\right.$ at $\left.+25^{\circ} \mathrm{C}\right)$ \\
4 & Rated for full $-55^{\circ}$ to $+150^{\circ} \mathrm{C}$ range \\
5 & Operates from 4 to 30 volts \\
6 & Less than $60 \mu \mathrm{A}$ current drain \\
7 & Low self-heating, $0.08^{\circ} \mathrm{C}$ in still air \\
8 & Nonlinearity only $\pm 1 / 4^{\circ} \mathrm{C}$ typical \\
9 & Low impedance output, 0.1 W for $1 \mathrm{~mA}$ load \\
10 & Suitable for remote applications \\
11 & Low cost due to wafer-level trimming \\
\hline
\end{tabular}

\section{b. Mikrokontroler AVR}

Pengolahan data pembacaan sensor suhu dilakukan oleh mikrokontroler berbasis AVR dan open source. Penelitian ini menggunakan chip mikrokontroler 8-bit berbasis AVR-RISC. Dilengkapi dengan $32 \mathrm{~KB}$ memori, ISP flash dengan kemampuan read-write sebesar $32 \mathrm{~KB}, 1$ KB EEPROM dan 2 KB SRAM.

Beberapa fitur keunggulan lainnya adalah adanya 20 jalur GPIO yang terdiri dari 6 pin analog dan 14 pin digital, 32 register, 3 timer/counter, interupt internal dan external, serial programmable USART dan 6 channel 10bit A/D converter. Chip ini beroperasi pada tegangan kerja antara $1.8 \mathrm{~V}-5.5 \mathrm{~V}$ [5]. Spesifikasi mikrokontroler sebagaimana tersebut dapat dilihat pada tabel 2.

Tabel 2. Spesifikasi Mikrokontroler

\begin{tabular}{ll}
\hline & Spesifikasi mikrokontroler \\
\hline Tipe & ATMega 328 \\
Tegangan operasi & $5 \mathrm{~V}$ \\
Tegangan input yang disarankan & $7-12 \mathrm{~V}$ \\
Batas tegangan input & $6-20 \mathrm{~V}$ \\
Jumlah pin I/O digital & 14 pin $(6$ pin PWM $)$ \\
Jumlah pin analog & $6 \mathrm{pin}$ \\
Arus DC tiap pin I/O & $40 \mathrm{~mA}$ \\
Arus DC untuk pin 3,3 V & $50 \mathrm{~mA}$ \\
Memori flash & $32 \mathrm{~KB} \mid 0,5$ untuk bootloader \\
\hline
\end{tabular}

\section{c. Modul Komunikasi GSM GPRS}

Proses komunikasi pada penelitian ini menggunakan produk dari SIMCOM tipe SIM900a yang berfungsi sebagai media penghubung antara sensor dan website. Modul ini bekerja pada band frekuensi $900 \mathrm{MHz}$ dan 1800 $\mathrm{MHz}$ dan berdaya rendah. Kedua keutamaan ini sudah cukup digunakan sebagai perantara pengirim data. Dikombinasikan dengan mikrokontroler nantinya didapatkan fitur berupa sms, telepon dan pengiriman data GPRS. Di modul juga terdapat slot untuk menempatkan simcard yang kompatibel dengan produk dalam negeri. Proses komunikasi pengiriman data sensor menuju website cukup dengan mengaktifkan paket GPRS yang terdapat pada slot kartu GSM. Spesifikasi modul SIM900a dapat dilihat pada tabel 3 .

Tabel 3. Spesifikasi SIM900a

\begin{tabular}{ll}
\hline No. & \multicolumn{1}{c}{ Fitur SIM 900a } \\
\hline 1 & GPRS multi-slot class 10/8 \\
2 & GPRS mobile station class B \\
3 & Support SMS, MMS \\
4 & Rentang catu daya $7-12 \mathrm{~V}$ \\
5 & Memenuhi standar GSM 2/2+ \\
6 & Pengendalian lewat perintah AT \\
7 & Rentang suhu operasional $-40{ }^{\circ} \mathrm{C}$ sampai dengan $85^{\circ} \mathrm{C}$ \\
8 & Pengendalian lewat perintah AT \\
9 & Rentang suhu operasional $-40{ }^{\circ} \mathrm{C}$ sampai dengan $85^{\circ} \mathrm{C}$ \\
\hline
\end{tabular}

\section{d. Online monitoring}

Proses monitoring dilakukan melalui website berdasarkan masukan data dari sensor. Pencatatan data suhu dalam satuan derajat Celcius yang terpantau setiap 10 menit. Pengiriman data suhu ditampung di server Thingspeak. Melalui server ini nantinya diperlukan beberapa pengaturan, supaya data suhu yang terpantau dapat memudahkan analisis lebih lanjut.

\section{METODE}

a. Diagram kerja sistem

Proses kerja sistem secara keseluruhan terbagi menjadi beberapa blok bagian. Pembagian sistem kerja dapat diketahui melalui tiga bagian utama, yaitu pengambilan data, pengiriman dan monitoring.

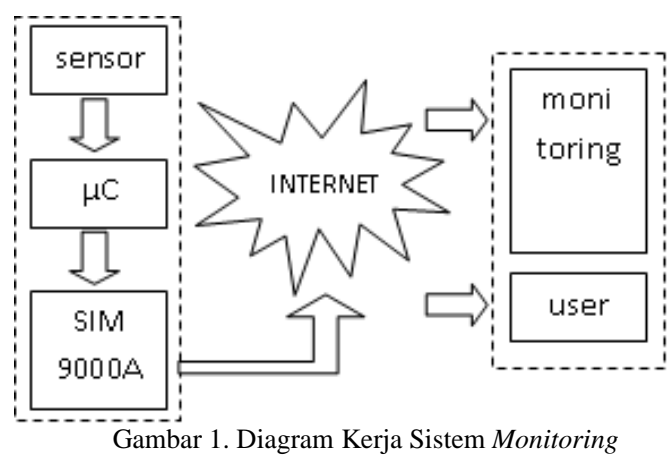

Sensor membaca nilai suhu dengan besaran derajat satuan Celcius. Nilai suhu selanjutnya diolah oleh mikrokontroler untuk dikirimkan datanya melalui modul SIM900a. Data besaran suhu ditampilkan melalui server Thingspeak dan di monitoring oleh user.

b. Flowchart Sistem

Alur sistem monitoring secara keseluruhan tidak hanya melibatkan sekumpulan modul, namun juga urutan kerja masing-masing bagian. Berisi penjelasan lebih lanjut mengenai alur sistem kerja yang didetilkan. Hal ini disajikan di gambar 2 . 


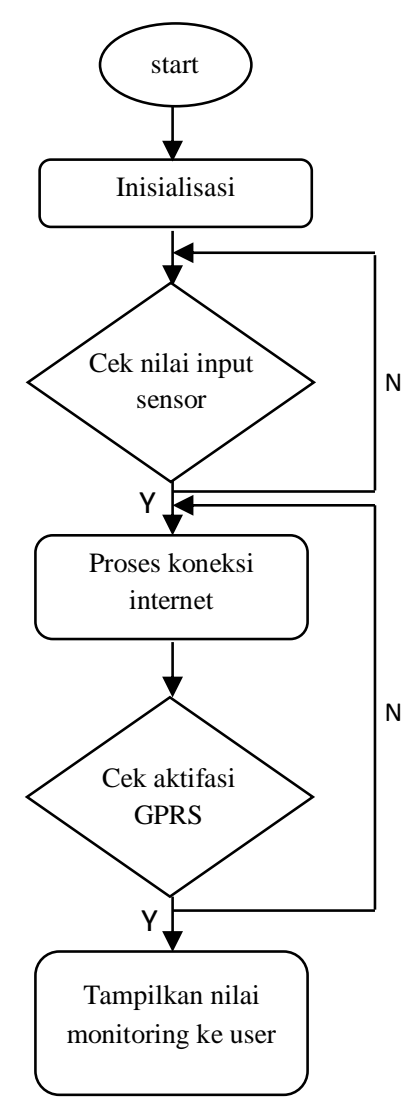

Gambar 2 Flowchart Monitoring

Instalasi sensor suhu di mikrokontroler memerlukan pengetahuan seputar hardware LM35. Terdapat 3 pin diantaranya VCC, Vout dan GND. Melalui Vout inilah didapatkan besaran suhu lingkungan. Tegangan kerja yang dibutuhkan sensor berkisar antara 3-5,5 VDC melalui port mikrokontroler. Alur program menghendaki adanya pengecekan secara terus menerus sebagai bentuk antisipasi perubahan suhu lingkungan yang seketika terjadi. Proses pengecekan ini mengharuskan adanya catu daya yang stabil untuk kelancaran inisialisasi. Jika terjadi permasalahan di catu daya, maka pembacaan nilai sensor menjadi error dan akan dilakukan proses pembacaan ulang sampai didapatkan besaran nilai suhu tertentu.

Pembacaan sensor suhu dapat dilakukan dalam rentang waktu tertentu sebagaimana pengaturan di mikrokontroler. Pengecekan selalu dilakukan untuk memastikan adanya nilai suhu tertentu. Jika hasil pembacaan menghasilkan besaran nilai suhu tertentu, maka nilai yang didapat selanjutnya ditransfer menuju ke web server.

Penelitian ini menggunakan web server Thingspeak, dimana banyak beberapa rekomendasi untuk menggunakan platform tersebut. Untuk bisa mengakses server Thingspeak diperlukan beberapa konfigurasi yang dilakukan melalui mikrokontroler. Konfigurasi ini berhubungan dengan pemakaian modul SIM900a. Pengecekan konektivitas internet akan terus dilakukan untuk memastikan bahwa seperangkat alat rancang bangun monitoring selalu terhubung. Hal ini dilakukan untuk keperluan transfer data menuju web server. Pemakaian modul SIM900a mengharuskan adanya simcard dengan status paket data internet aktif. Jika dijumpai adanya masalah konektivitas internet, maka akan dilakukan pengulangan proses koneksi. Selanjutnya jika dipastikan bahwa koneksi internet tidak ada masalah menuju web server, maka nilai masukan data sensor suhu dapat diteruskan.

Tampilan besaran suhu di server Thingspeak menyesuaikan pengaturan besaran satuan di mikrokontroler. Penelitian ini menggunakan besaran suhu dalam satuan Celcius. Beberapa pengaturan di server Thingspeak harus dilakukan untuk menunjang proses monitoring. Server Thingspeak menyediakan pemakaian bebas pakai untuk berbagai keperluan. Salah satu pemanfaatan server ini bisa dikonfigurasi untuk keperluan monitoring. Penggunaan server Thingspeak mengharuskan adanya registrasi user.

\section{c. Proses Koneksi Server}

Kestabilan catu daya menjadi penting diperhatikan untuk menjamin proses komunikasi transfer data berjalan lancar. Modul perantara komunikasi server menggunakan SIM900a yang membutuhkan catu daya stabil sebesar 5.5 VDC. Input tegangan untuk mikrokontroler yang terhubung dengan SIM900a perlu disesuaikan melalui modul DC-DC Buck Converter Step Down Adjustable. Spesifikasi modul DC-DC Buck Converter Step Down dapat dilihat di tabel 4.

Tabel 4 DC-DC Buck Converter Step Down

\begin{tabular}{ll} 
Regulator type & $\begin{array}{l}\text { Step down (non isolated input to } \\
\text { output) } \\
\\
\text { Input voltage }\end{array}$ \\
Output voltage & +1.23 to $35 \mathrm{VDC}$ \\
Output current & $2 \mathrm{~A}$ rated (3A maximum with \\
& heatsink) \\
Efficiency & Up to $92 \%$ (when output voltage \\
& is set high) \\
Switching frequency & $150 \mathrm{KHz}$ \\
Dropout voltage & $2 \mathrm{VDC}$ minimum \\
Protection & Short circuit current limiting \\
Load regulation & $\pm 0.5 \%$ \\
Voltage regulation & $\pm 2.5 \%$ \\
Temperature & -40 to $+85^{\circ} \mathrm{C}$ (output power less \\
& than 10 watt) \\
\hline
\end{tabular}

Penyesuaian tegangan input SIM900a dapat dilakukan melalui potensiometer yang terdapat di DC-DC Buck Converter Step Down modul. Kestabilan tegangan yang didapat modul SIM900a, ditandai adanya led merah yang berkedip setiap saat. Pastikan simcard yang terpasang di modul SIM900a sudah diaktifkan fitur GPRS dan dapat terkoneksi ke server.

\section{d. Server Thingspeak}

Sistem online monitoring memerlukan protokol MQTT server yang harus mempunyai kemampuan menyimpan pencatatan data. Membangun server ini memerlukan beberapa infrastruktur yang meliputi publisher, subscriber dan broker. Porsi utama server monitoring lebih kepada broker yaitu kemampuan sebagai penghubung antara publisher dan subsciber.

Layanan infrastruktur online dapat dijumpai dengan memanfaatkan opensource IOT server. Thingspeak merupakan salah satu diantara server monitoring yang opensource. Layanan yang disajikan meliputi free broker, free logging dan free API (Application Programming Interface). Untuk dapat menikmati layanan server 
Thingspeak, setiap user harus melakukan beberapa tahapan registrasi.

\section{HASIL DAN PEMBAHASAN}

a. Perhitungan sensor suhu

Penelitian ini menggunakan tegangan referensi default sebesar 5 V DC. Sensor suhu digunakan sebagai input data analog untuk diolah ke dalam mikrokontroler. Proses konversi dibutuhkan untuk mengolah data analog menjadi digital. Dikarenakan mikrokontroler memiliki ADC 10 bit, maka proses pencacahan data analog bermula dari 0 sampai 1023. Proses ini menyesuaikan dengan tegangan referensi yang diartikan 0 adalah 0 volt dan 1023 adalah 5 volt. Proses pencacahan tegangan 5 volt kedalam 1024 cacahan dihitung menjadi :

$\frac{5}{1024}=0.004883$ volt

Sensor suhu yang digunakan mencatat setiap $10 \mathrm{mV}$ terjadi kenaikan sebesar $1^{\circ} \mathrm{C}$. Oleh karena itu diperlukan perhitungan untuk mengetahui kenaikan suhu setiap cacahan.

$1^{o} \mathrm{C}=\frac{10 \mathrm{mV}}{4.883 \mathrm{mV}}$

Sehingga diketahui bahwa kenaikan sebesar $1^{\circ} \mathrm{C}$ terjadi 2.0479 cacahan. Dengan demikian rumus menghitung suhu menggunakan sensor LM35 adalah

suhu $=\frac{\text { nilai input sensor }}{2.0479}$

b. Koneksi web server

Terdapat beberapa langkah untuk mengatur koneksi internet menggunakan kombinasi SIM900a dan simcard, diantaranya :

1. Setting Access Point Name sesuai simcard. Langkah ini ditempuh dengan memasukkan ketentuan APN sesuai provider kartu pada bagian script :

$\mathrm{AT}+\mathrm{CSTT}=\backslash "($ APN simcard $) \backslash " "$

2. Setting protokol atau alur data

$\mathrm{AT}+\mathrm{CIPSTART}=\backslash$ "TCP $\backslash ", \backslash$ "api.thingspe ak. com \", \"80\"

Pengaturan ini menyesuaikan tempat server yang digunakan untuk keperluan monitoring.

3. Setting Application Programming Interface key server

API key didapatkan dengan cara generate otomatis dari web server.

str $="$ GET

http://api.thingspeak.com/update?a pi_key=(setting API) \&fieldl="

Nilai API key bisa berubah-ubah setiap waktu.

\section{c. Error data}

Terdapat perbedaan nilai suhu antara tampilan di LCD 16x2 dan pencatatan di server Thingspeak. Hal ini dapat disajikan melalui gambar dan tabel berikut.

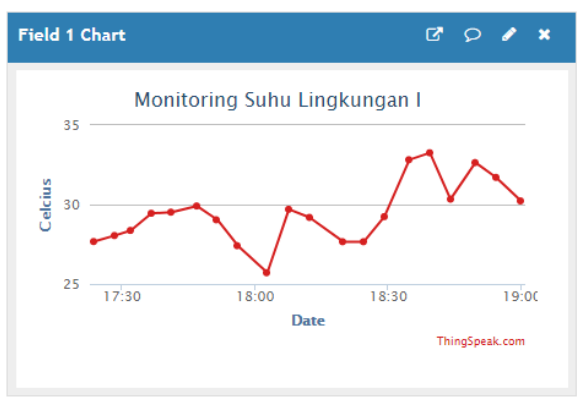

Gambar 3. Monitoring Suhu Lingkungan I

Gambar 3 dan tabel 5 dilakukan pembacaan sensor di tempat suhu ruangan. Pada percobaan ini didapatkan error rata-rata sebesar 0.0235 .

Tabel 5. Hasil Sensing Sensor I

\begin{tabular}{lccc}
\hline No & $\begin{array}{c}\text { Pembacaan } \\
\text { Alat }\end{array}$ & $\begin{array}{c}\text { Pendataan } \\
\text { Server }\end{array}$ & Error \\
\hline 1 & 27.79 & 27.77 & 0.02 \\
2 & 28.28 & 28.25 & 0.03 \\
3 & 28.07 & 28.04 & 0.03 \\
4 & 29.07 & 29.06 & 0.01 \\
5 & 29.15 & 29.12 & 0.03 \\
6 & 29.37 & 29.35 & 0.02 \\
7 & 29.13 & 29.12 & 0.01 \\
8 & 27.14 & 27.11 & 0.03 \\
9 & 25.32 & 25.31 & 0.01 \\
10 & 29.54 & 29.52 & 0.02 \\
11 & 29.18 & 29.15 & 0.03 \\
12 & 27.51 & 27.50 & 0.01 \\
13 & 27.19 & 27.16 & 0.03 \\
14 & 29.18 & 29.14 & 0.04 \\
15 & 32.15 & 32.12 & 0.03 \\
16 & 33.07 & 33.06 & 0.01 \\
17 & 30.14 & 30.12 & 0.02 \\
18 & 32.53 & 32.50 & 0.03 \\
19 & 31.36 & 31.33 & 0.03 \\
20 & 30.23 & 30.20 & 0.03 \\
\hline
\end{tabular}

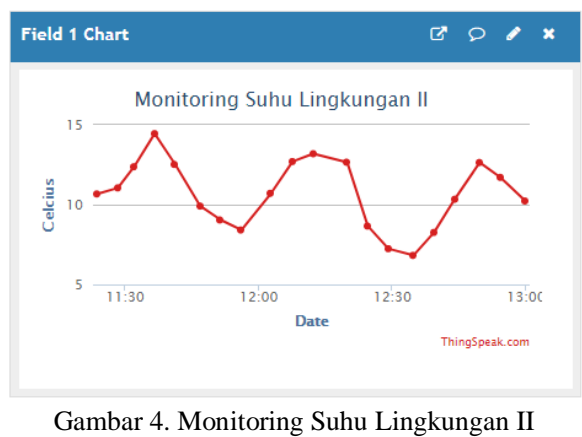

Gambar 4 dan tabel 6 dilakukan pembacaan sensor di tempat dengan suhu lebih rendah dibandingkan percobaan pertama. Pada percobaan ini didapatkan error rata-rata sebesar 0.0225 .

\begin{tabular}{lccc}
\multicolumn{4}{c}{ Tabel 6. Hasil Sensing Sensor II } \\
\hline No. & $\begin{array}{c}\text { Pembacaan } \\
\text { Alat }\end{array}$ & $\begin{array}{c}\text { Pendataan } \\
\text { Server }\end{array}$ & $\begin{array}{c}\text { Error } \\
\text { Data }\end{array}$ \\
\hline 1 & 10.68 & 10.67 & 0.01 \\
2 & 11.07 & 11.05 & 0.02 \\
3 & 12.39 & 12.37 & 0.02 \\
4 & 14.46 & 14.45 & 0.01 \\
5 & 12.55 & 12.52 & 0.03 \\
6 & 9.92 & 9.91 & 0.01 \\
7 & 9.06 & 9.04 & 0.02 \\
8 & 8.43 & 8.41 & 0.02 \\
9 & 10.74 & 10.71 & 0.03 \\
10 & 12.73 & 12.70 & 0.03 \\
11 & 13.23 & 13.19 & 0.04 \\
\hline
\end{tabular}




\begin{tabular}{lccl}
\hline 12 & 12.67 & 12.66 & 0.01 \\
13 & 8.68 & 8.66 & 0.02 \\
14 & 7.27 & 7.24 & 0.03 \\
15 & 6.86 & 6.82 & 0.04 \\
16 & 8.29 & 8.26 & 0.03 \\
17 & 10.37 & 10.34 & 0.03 \\
18 & 12.67 & 12.64 & 0.03 \\
19 & 11.72 & 11.71 & 0.01 \\
20 & 10.24 & 10.23 & 0.01 \\
\hline
\end{tabular}

\section{KESIMPULAN}

Telah berhasil dilakukan sistem rancang bangun monitoring suhu lingkungan berbasis internet of things. Sistem ini bersifat portable sehingga bisa ditempatkan di manapun tanpa harus terkoneksi di wifi area. Terdapat nilai pengujian pembacaan error rata-rata antara tampilan LCD dan server Thingspeak sebesar 0.0235 di tempat pertama dan 0.0225 di tempat kedua.

Hasil pengujian sistem rancang bangun ini nantinya dapat dikembangkan untuk keperluan analisis lanjutan terkait suhu kondisi lingkungan.

\section{REFERENSI}

[1] Prasetyo Diyan Rebiyanto, Ahmad Rofii, Rancang Bangun Sistem Kontrol Dan Monitoring Kelembaban Dan Temperature Ruangan Pada Budidaya Jamur Tiram Berbasis IOT, 2018, Jurnal Kajian Teknik Elektro vol. 02 no. 02, Universitas 17 Agustus 1945, Jakarta

[2] Jacquline Waworundeng, Oktoverano Lengkong, Sistem Monitoring dan Notifikasi Kualitas Udara dalam Ruangan dengan Platform IOT, 2018, Cogito Smart Jurnal vol. 04 no. 1, Universitas Klabat, Airmadidi

[3] Fathur Zaini Rachman, Sistem Pemantau Gas di Tempat Pembuangan Sampah Akhir Berbasis Internet of Things, 2018, Jurnal Teknologi dan Sistem Komputer vol. 06 no. 03, Politeknik Negeri Balikpapan, Balikpapan

[4] Datasheet LM35

[5] Datasheet arduino

[6] Datasheet sim900a

[7] Datasheet DC-DC Buck Converter Step Down 